\section{EL GRECO EN ESPAÑA. EL ÉXITO DE UN GRAN PINTOR}

\author{
Agustín Bustamante García \\ Universidad Autónoma de Madrid \\ agustin.bustamante@uam.es
}

Cómo citar este artículo/Citation: Bustamante García, A. (2015). "El Greco en España. El éxito de un gran pintor". Arbor, 191 (776): a274. doi: http://dx.doi.org/10.3989/ arbor.2015.776n6001

Recibido: 22 diciembre 2014. Aceptado: 9 marzo 2015.

RESUMEN: El Greco es un pintor reconocido por sus contemporáneos. De tradición bizantina cretense, marchó a Italia en 1567. En Venecia y Roma configuró su arte sobre el naturalismo de la luz y del color y adquiriendo una formación teórica, que le convertirá en filósofo de agudos dichos. No triunfó en Italia, desplazándose a España en 1577, donde permanecerá hasta morir en 1614. Triunfó en Toledo pintando para la Catedral y Santo Domingo el Antiguo. Felipe II le llamó al Escorial. El Entierro del Señor de Orgaz fue un cuadro famoso y carísimo nada más pintarse. Desde 1596 Theotocópuli consiguió grandes encargos: los retablos de doña María de Aragón en Madrid, el del Monasterio de Guadalupe, la Capilla de San José de Toledo, el Hospital de la Caridad de Illescas y los del Hospital Tavera. Es el mejor retratista de su época, pintando además de temas religiosos, mitologías y vistas. Un triunfador.

PALABRAS CLAVE: El Greco; Creta; Italia; España; Venecia; Roma; Toledo; Felipe II; El Escorial.

\section{EL GRECO IN SPAIN. THE SUCCESS OF A GREAT PAINTER}

Copyright: (C) 2015 CSIC. Este es un artículo de acceso abierto distribuido bajo los términos de la licencia Creative Commons Attribution-Non Commercial (by-nc) Spain 3.0.
ABSTRACT: El Greco was a painter who was already recognised by his contemporaries. With a Byzantine-Cretan tradition, he moved to Italy in 1567. In Venice and Rome he developed his art based on the naturalism of light and colour and also acquired a theoretical education, turning him into a philosopher known for his sharp sayings. Failing to find success in Italy he moved to Spain in 1577, where he remained until his death in 1614 . He found success in Toledo, where he painted for the Cathedral and for the church of Santo Domingo el Antiguo. Philip II asked him to work at El Escorial. The picture of the Burial of the Count of Orgaz became famous and expensive as soon as it was painted. In 1596 Theotocópoulos began to receive important commissions: the altarpieces for the Doña María de Aragón in Madrid, for the Guadalupe Monastery, for the chapel of San José in Toledo, for the Hospital de la Caridad in Illescas and for the Hospital Tavera. He was the best portraitist of his time, painting mythologies and landscapes, as well as religious themes. A success.

KEYWORDS: El Greco; Crete; Italy; Spain; Venice; Rome; Toledo; Philip II; El Escorial. 
El cretense Doménikos Theotokópoulos, conocido por los españoles de su época como El Griego, fue un pintor extraordinario dotado con una fuerte personalidad, opinión que se ha mantenido hasta nuestros días, confirmada por las múltiples noticias que se han ido descubriendo del artista. En España, donde interesa más el arte que los artistas, resulta un hecho de todo punto extraordinario que el nombre del pintor cretense apareciera en letra impresa y fuese ya citado en 1588 por Alonso de Villegas en ese éxito editorial incomparable que fue el Flos Sanctorum (Villegas, 1614). El escritor toledano le llama Dominico Theotocópuli de nación Griego, italianizando su nombre, como harán otros Ilamándole Greco. No es extraño ese fenómeno, pues el artista vivió diez años en Italia. Cuando llegó a España, la lengua que empleaba era el italiano y su arte era italiano, repleto de rasgos de Venecia y Roma, las dos ciudades donde más tiempo vivió. El español de El Greco está repleto de italianismos (Marías Franco y Bustamante, 1981), así que no es nada extraño, no solo que los pagadores del Escorial le tomasen por italiano, sino que se le llamase por su nombre italianizado, como lo harán fray José de Sigüenza en 1605 (Sigüenza, 1963) y Francisco Pacheco en 1611 (Pacheco, 1611/1990): Dominico Greco.

La personalidad del pintor cretense y su arte fueron todo un episodio en su época. La unión de una fuerte personalidad con un arte extraordinario, cuya calidad solo podía ser replicada por Juan Fernández de Navarrete el Mudo, le llevaron a la fama, al éxito y a la polémica. Para colmo, Theotocópuli trae a España la pugna tan italiana del diseño y el color, apostando por este último frente al primero, causando un auténtico escándalo en Francisco Pacheco, cuando lleva la pugna a lo superlativo y dice a su huésped sevillano, que Miguel Angel era un buen hombre, y que no supo pintar.

Las diferencias entre Pacheco y El Greco no impiden al andaluz mantener su postura contraria, si bien siente una profunda admiración por el toledano, le tiene un gran respeto y las diferencias, a las que llama opiniones y paradojas suyas, no le hacen perder la compostura, y le reconoce varias veces, entre otras cosas de gran valor, que está entre los grandes pintores, que hay cosas de su mano que igualan a las de los mayores hombres, y que tiene aquella su manera, es decir, estilo, esa forma de pintar que le hace inconfundible y único. Pero Pacheco fue a más: Theotocópuli era un trabajador incansable, teniendo en su taller una alacena con figuras, que empleaba como modelos para sus composiciones pictóricas, como toda una habitación en donde tenía en pequeño todos los cuadros que había pintado. Este trabajo sistemático y continuado lo confirma el propio Greco de forma autógrafa, cuando insiste una y otra vez en el dibujar y más dibujar. Pero la base de esta tarea no es mecánica, sino fruto de la reflexión, es decir, de la noción de disegno albertiana, donde la función reflexiva, depurada por el conocimiento, es la clave de toda la actividad humana, y por tanto artística. Significativamente, la biblioteca de El Greco estaba en su taller, es decir, era un instrumento más de su trabajo (Riello, 2014). El conocimiento y el virtuosismo técnico permiten, tanto un enriquecimiento de la imaginación, como la valentía, es decir, la búsqueda de la dificultad y que el enorme esfuerzo no sea visible, es decir, la sprezzatura. Pacheco describe este modo de trabajar de forma meridiana: Otros labran el bosquexo y, al acabado, usan de borrones, queriendo mostrar que obran con más destreza y facilidad que los demás y costándoles esto mucho trabajo lo disimulan con este artificio, porque ¿quién creerá que Dominico Greco traxese sus pinturas muchas veces a la mano, y las retocase una y otra vez, para dejar los colores distintos y desunidos y dar aquellos crueles borrones para afectar valentía? A esto llamo yo trabajar para ser pobre (Pacheco, 1611/1990). Esta mezcla de admiración y crítica, de fascinación y escándalo, que es lo que caracteriza la relación de Pacheco con El Greco, no le impide situarlo en los niveles más altos del arte y de la sabiduría, diciendo de él: Dominico Greco, que fue gran filósofo de agudos dichos y escribió de la pintura, escultura y arquitectura.

Francisco Pacheco está en línea con fray José de Sigüenza en lo que se refiere al artista cretense, pero el carácter acrimónico del monje jerónimo, le sitúan en las antípodas del templado pintor sevillano. Hablando de la ornamentación escurialense, fray José dedica un párrafo a El Greco y a una de sus obras maestras: De un Dominico Greco, que ahora vive y hace cosas excelentes en Toledo, quedó aquí un cuadro de San Mauricio y sus soldados, que le hizo para el propio altar de estos santos; no le contentó a Su Majestad (no es mucho), porque contenta a pocos, aunque dicen es de mucho arte y que su autor sabe mucho, y se ve en cosas excelentes de su mano (Sigüenza, 1963). El jerónimo no puede evitar recoger la opinión de que la obra es de mucho arte y que su autor sabe mucho, y lo confirman además las cosas excelentes de su mano. Estamos, por tanto, a comienzos del siglo XVII, en una clara coincidencia entre Sigüenza y Pacheco: El Greco como un artista que sabe mucho y hace obras excelentes (Bustamante García, 1992). 
La fama de El Greco no desaparece, a pesar de algunos silencios clamorosos, como el de los Diálogos de la Pintura de Vicente Carducho de 1633 (Carducho, 1979); sin embargo su figura histórica se va diluyendo, transformándose en leyenda en la segunda mitad del siglo XVII, y en ello juegan un papel primordial sus colegas pintores, en especial Jusepe Martínez hacia 1675 (Martínez, 2006) y Antonio Palomino, cuya obra se publicará ya en el siglo XVIII (Palomino, 1947). Para Jusepe Martínez Theotocópuli es un hombre extravagante, a igual que su arte y toda su vida, ganando grandes fortunas y gastándolas con gran velocidad. Semejante forma de ser y vivir le llevó a no tener discípulos (Pita Andrade, 1984). Pero la leyenda tuvo un éxito sonado hasta el siglo XX.

La visión de Antonio Palomino tuvo una repercusión mucho mayor, pues él elabora la primera biografía del pintor cretense al estilo de Giorgio Vasari, es decir, una biografía humanística de hombre ilustre, recogiendo que es griego de nación, discípulo de Tiziano, al que imitó, y que se parecía tanto a su maestro en el estilo, y en particular en las cabezas y retratos, que sus obras se confundían con las del pintor de Cadore. Por ello decidió mudar de manera, con tal extravagancia, que llegó a hacer despreciable y ridícula su pintura, así en lo descoyuntado del dibujo, como en lo desabrido del color. A pesar de esos aspectos cuanto menos extravagantes, Palomino ensalza, no solo que era un gran pintor y un varón docto en su profesión, denominándole gran filósofo y de agudos dichos. Además de pintor fue escultor y arquitecto y abanderado en la defensa de la ingenuidad del arte de la pintura, frente a las exigencias del Alcabalero de Illescas, punto de partida de todo un movimiento de los artistas que se extendió durante todo el siglo XVII y parte del XVIII, y que sentó la leyenda de que el gran artista toledano no vendía sus cuadros, sino que los empeñaba, pues él no comerciaba con su arte (Gállego, 1976). El texto de Palomino, con más o menos variantes, será la guía de los estudiosos y hombres de gusto del siglo XVIII, tanto españoles, como extranjeros (Pita Andrade, 1984).

A partir del siglo XIX todo el arte español, y con él El Greco, entrarán en una nueva dimensión, cuyos límites transcurren entre la agudeza y el disparate, la búsqueda del rigor entrelazado con el prejuicio. A pesar de todo ello el arte español se va abriendo camino (Bustamante García, 2000; Bustamante García, 2003a; Bustamante García, 2005), y, como es natural, Theotocúpuli ocupa un lugar destacado, polémico e innovador (Álvarez Lopera, 1987). El siglo XX es el de las grandes investigaciones sobre el artista toledano, el cual es visto como un auténtico genio del arte español, cuya obra es espejo para las vanguardias; su forma de vivir y de pintar hacen del artista una figura completamente actual, merecedora de multitud de monografías, artículos y exposiciones, y cuya bibliografía no para de crecer (Álvarez Lopera, 2005; Álvarez Lopera, 2007; Marías, 2013). Es la época, además, en que Manuel Bartolomé Cossío transforma a Dominico en un pintor místico, que sabe reflejar a la perfección el alma española de un mundo en decadencia (Cossío, 1972) cuya otra pata es el Quijote de Miguel de Cervantes. En la actualidad hay diversas posiciones enfrentadas respecto a la figura y la obra de Doménikos Theotokópoulos, tanto en España, como fuera de ella. Una vez más, El Greco es un tema candente a comienzos del siglo XXI.

En este transcurrir de la vida y fama del pintor cretense, siempre polémico y a veces sumergido por los estudiosos en laberintos incomprensibles, tiende a perderse de vista algo decisivo: a través de los azares de su vida, Dominico Greco logró triunfar en España. Sus contemporáneos le reconocían un valor incomparable y pudo montar su taller y vivir muy dignamente de su trabajo. A El Greco nunca le faltaron encargos, a pesar de su carácter fuerte y de los muchos disgustos que le daban sus clientes, lo que le llevaba al enfrentamiento y acabar las diferencias en los tribunales. Y ese éxito lo tuvo que conseguir desde la nada, luchando a brazo partido para abrirse camino en la vida, primero en Creta, después en Italia y, finalmente, en España.

Doménikos Theotokópoulos, nació en Candía, la actual Iraklion, en la isla de Creta en 1541, en una familia de comerciantes vinculados al dominio veneciano, cuyos negocios a veces eran tan poco recomendables como el corso, el rescate y la trata de esclavos, pero todos ellos muy lucrativos. Doménikos aprendió el oficio de pintor en su ciudad natal. Sus primeras obras muestran su perfecto conocimiento de la manera bizantina y el modo de hacer iconos. En 1563 ya tenía título de maestro pintor. Pero desde el principio, según se deduce de sus obras conservadas, tenía especial fascinación por las corrientes modernas del Renacimiento, completamente ajenas a lo bizantino, incorporando a sus obras, referencias y elementos, sacados la mayor parte de ellos de grabados, que perturbaban la inmutabilidad de la pintura sacra bizantina. Esta situación que Theotokópoulos muestra en su Creta natal, no parece que fuese la mejor manera de ganarse un mercado artístico como el candiota, donde el arte religioso es lo predominante. Lo 
conservado de El Greco en su etapa cretense es arte sacro, mereciendo destacar tres piezas excelentes: San Lucas pintando a la Virgen, del Museo Benaki de Atenas (ca. 1563-1566); la Dormición de la Virgen (ca. 1565-1566), en la iglesia de la Koimesis de Ermúpolis, en la isla de Syros, y, finalmente, la Epifanía (ca. 1565-1567), también en el Museo Benaki de Atenas, y que para algunos estudiosos ya debió ser pintada en Venecia. Las dos primeras, sobre su raíz bizantina de iconos, se van transformando con la introducción de citas clásicas extraídas de grabados renacentistas, mientras que la Epifanía, sencillamente, es una obra ya pintada según los criterios del arte renacentista, por completo diferente a la tradición bizantina. Todos estos aspectos han merecido una abundante atención por los estudiosos del mundo de El Greco (Hadjinicolaou, 1995 y 1999; Álvarez Lopera, 2005 y 2007; Hadjinicolaou, 2007; Panagiotakes, 2009; Marías, 2013; Marías, 2014). En 1567 Doménikos abandonó para siempre su tierra natal camino de Venecia, dejando como legado una corta obra de pequeño formato. Dada la juventud del pintor y sus aspiraciones, era lo más comprensible.

El Greco llegó a Venecia con veintiséis años; era súbdito de la Serenísima, puesto que Creta formaba parte del imperio veneciano. La ciudad era un emporio de poder y riqueza; su flota era temible y ofrecía una tenaz resistencia a la presión marítima turca. Venecia no estaba dispuesta a aliarse con nadie; su política exterior era buscar su interés por encima de todo, y para ello firmaba pactos con los turcos, combinando distensiones militares y acuerdos económicos, especialmente intentando salvaguardar las relaciones comerciales con Oriente. Este imperio veneciano en retroceso, pero en absoluto vencido, tenía en Venecia un poderosísimo centro financiero, comercial, político y cultural de primer orden, incrementado por la enorme seguridad con que se vivía en Venecia y en toda la Terra Ferma. Dominico Theotocópuli vivirá en Venecia tres años. La ciudad era un foco artístico formidable, con una actividad y un mercado potentísimos y muy activos. El punto crítico era entrar en él, y aquello era muy difícil viniendo de Levante.

Por sus obras y sus testimonios manuscritos pueden hacerse sólidas deducciones sobre la evolución de El Greco. El artista ve mucho, lee mucho y adquiere multitud de grabados, pues Venecia es uno de los lugares de Europa de mayor potencia editorial. Pero es que, además, Venecia es el lugar donde se considera que la pintura es sobre todo color, y no dibujo como sostienen florentinos y romanos.
El culto al colorido, la importancia de las relaciones tonales, las consecuencias de la luz y el color sobre la forma de ver y representar, que desde Giorgione será una constante en la escuela veneciana hasta su desaparición en el siglo XVIII, y que tendrá su apogeo en el siglo XVI con Tiziano, Palma el Viejo, Sebastiano del Piombo, Tintoretto, Veronese, los Bassano y Palma el Joven, por citar las cumbres más altas, se complementa con todo un desarrollo de la teoría del color y la aparición de tratados sobre el particular, como la producción de Lodovico Dolce, en especial su Dialogo della Pittura, intitolato L'Aretino, Venecia, 1557. El Greco es un defensor a ultranza del color, es un veneciano, a pesar de su admiración por el dibujo y su mucho estudio (Zeitler y Hellwig, 2006). Como persona de la escuela veneciana, siente una profunda admiración hacia Tiziano, aunque no está nada claro que estuviera en su taller, a pesar de toda la tradición que le hace discípulo del de Cadore. Por el contrario, el cretense no se para en barras a la hora de alabar y ensalzar a Jacopo Tintoretto, como lo refleja en sus anotaciones a Vasari (Salas y Marías Franco, 1992).

Pero la producción veneciana de El Greco que conocemos es muy escasa y toda ella de pequeño formato. En la Ultima Cena de la Pinacoteca Nazionale de Bolonia (ca. 1568), como en la Huída a Egipto de una colección particular londinense (ca. 1569), puede verse como Theotocópuli asimila a gran velocidad todas las formas renacentistas venecianas, tanto de representaciones en interiores, como de escenas en paisaje, y como introduce elementos originales en historias tratadas de continuo y desde largo tiempo. Su mejor obra veneciana es el denominado Tríptico de Módena, de la Galleria Estense de esa ciudad (ca. 1568-1569). Temáticamente es de una gran originalidad y de un uso del color de lo más valiente; hay alardes de dominio de perspectiva, del cuerpo humano y del movimiento, y en él aparecen los primeros testimonios de su poética, que repetirá a lo largo de su vida, como los ángeles, las visiones terroríficas de las postrimerías con la boca del Infierno y la agitación de grupos, mientras que para lugares lejanos, como el monte Sinaí y el Monasterio de Santa Catalina recurre a los grabados (Hadjinicolaou, 1999; Álvarez Lopera, 2007; Marías, 2013; Marías, 2014), tanto en este tríptico, como en la tabla del Monte Sinaí del Museo Histórico de Creta en Iraklion, y que se considera hecho en Roma para Fulvio Orsini (ca. 1570-1572).

En 1570 Dominico Greco deja Venecia y se dirige a Roma en busca de mejor fortuna, lo que indica que sus aspiraciones no se veían cumplidas en la Ciudad 
de la laguna. Llegó a la Ciudad Eterna con una carta de presentación del miniaturista Giulio Clovio, escrita el 16 de noviembre de 1570, y dirigida a su patrón y protector desde hacía muchos años el Cardenal Alejandro Farnese. En ella dice que ha llegado a Roma un joven candiota discípulo de Tiziano, que a mi juicio, me parece raro en la pintura y, entre otras cosas, se ha hecho un autorretrato, que deja asombrados a todos los pintores de Roma.

Una vez más el Cardenal hacía caso a su protegido y servidor Clovio, como lo hiciera anteriormente cuando le recomendó a Federico Zuccari y a Bartolomé Spranger. El Greco entró al servicio del poderoso cardenal y vivía en el Palazzo Farnese. Las cosas parecían ir por buen camino. El artista entabló buena relación con el bibliotecario cardenalicio Fulvio Orsini, una de las grandes eminencias de su época, el cual, a su muerte, tenía siete cuadros del candiota, indicativos de lo que gustaba la pintura del cretense a ese egregio humanista. Tenía el retrato de Giulio Clovio (ca. 1570-1572) del Museo di Capodimonte en Nápoles, una pieza espectacular de venecianismo en Roma y una demostración de lo más aquilatada de su extraordinaria calidad como retratista. La segunda pieza era el Monte Sinaí, quizá la pintura de Iraklion. La tercera era un retrato de un muchacho con un gorro rojo y las cuatro restantes sendos tondos con las efigies del Papa Marcelo II, del Cardenal Besarión y de los cardenales Ranuccio y Alejandro Farnese. Todas estas pinturas las legó Orsini al Cardenal Odoardo Farnese, entrando de esta manera a formar parte de la colección Farnese. Acaso la obra más erudita, y todo un alarde de sabiduría pictórica, que llevó a cabo El Greco en Palazzo Farnese fue El muchacho encendiendo una candela, o Soplón (ca. 1572), hoy en Capodimonte. Identificada como una ékphrasis, cuya fuente se encuentra en la Historia Natural de Plinio el Viejo (Bialostocki, 1966). A su vez este cuadro, que se forma desde un fondo negro, donde el efecto de la luz y el colorido configuran la historia, es un alarde de como el naturalismo colorista y lumínico, elemento esencial de la pintura veneciana, permite la elaboración de una obra de extraordinarias cualidades, en línea con las investigaciones de Tiziano. El Soplón es toda una demostración del saber hacer de El Greco (Álvarez Lopera, 2005 y 2007; Marías, 2013; Marías, 2014).

Estando bajo la protección del Cardenal Farnese, El Greco pintará en Roma una serie de cuadros, que demuestra la asimilación completa de las formas renacentistas italianas, tanto venecianas, como lo mucho que aprende en Roma. La Expulsión de los merca- deres del Templo (ca. 1570) de la National Gallery of Art de Washington, y su variante del Institute of Fine Arts de Mineapolis (ca. 1572), así como la Curación del Ciego (ca. 1571) de la Gemäldegalerie de Dresde, y su variante de la Galleria Nazionale de Parma (ca. 1571-1572), son composiciones completamente italianas, con estructuras espaciales formadas a partir de la racionalización perspectiva del espacio, la disposición de las arquitecturas, de los grupos que están en ese espacio, y de la multitud de posibilidades que ofrece el cuerpo humano con sus movimientos y sus gestos. El Greco podía estar muy satisfecho con sus logros como artista.

Pero algo ocurrió de forma irreparable, que obligó al Cardenal Farnese a despedir al artista y echarlo ignominiosamente de su casa, de lo que se queja el pintor amargamente en carta autógrafa al Cardenal con fecha en Roma, a 6 de julio de 1572 (Pérez de Tudela, 2000 y 2001). Theotocópuli perdió a su protector; procuró con insistencia recuperar el favor, pero no lo consiguió. Había que empezar de nuevo y sin ningún protector.

El 18 de septiembre de 1572, Dominico pagaba dos escudos para matricularse en el gremio romano de los pintores, denominado con el pomposo título de Accademia di San Luca. A partir de ese momento podía ejercer como profesional de la pintura y tener taller. El Greco luchó denodadamente por abrirse camino en Roma. Conseguía encargos, pero de pequeña envergadura, como las dos pinturas de la Anunciación del Prado (ca. 1572) y de la Thyssen-Bornemisza (ca. 1576), ambas en Madrid y la excelente Adoración de los pastores (ca. 1572) de la Colección del Duque de Buccleuch, en Kettering (Northamptonshire), donde se puede ver como el artista vuelve sobre sus logros, para dar un nuevo paso adelante en sus composiciones de temas ya indagados. Aborda una nueva temática, como el asunto de la Piedad (ca. 1575), Nueva York, Hispanic Society of America, o la Magdalena penitente (ca. 1576) del Museo de Bellas Artes de Budapest, y se afianza como un retratista veneciano excelente con obras como el retrato de un anónimo personaje de la Galería Nacional de Copenhague (ca. 1574) y el de Vincenzo Anastagi (ca. 1575) en la Frick Collection de Nueva York.

Junto a esta actividad, Theotocópuli no dejaba de participar en las tendencias y discusiones artísticas de su época en Roma, según lo recogen fuentes italianas del siglo XVII, y que, a su vez lo corroboran las anotaciones que el pintor escribió en los volúmenes segundo y tercero de Le Vite de Giorgio Vasari, en la 
segunda edición corregida y aumentada, Florencia, 1568 (Salas y Marías Franco, 1992), y en las otras anotaciones manuscritas que escribió en un ejemplar del Vitruvio traducido al italiano y comentado por Daniele Barbaro, Venecia, 1556 (Marías Franco y Bustamante, 1981). En todas ellas, El Greco no solo tiene sus propios criterios y expone su pensamiento, sino que entra constantemente en polémica, llegando a veces al insulto personal, cosa que ocurre frecuentemente cuando hace frente a algún juicio o argumentación de Giorgio Vasari. Las opiniones de El Greco, que dejaron admirado y escandalizado a Francisco Pacheco, parece ser que también causaban un escándalo similar en Roma, según cuenta el médico papal Giulio Mancini hacia 1620 (Mancini, 1956). Viniendo la ocasión de tapar algunas figuras del Juicio de Miguel Angel que por Pío [V] se estimaban indecentes para aquel lugar, irrumpe [El Greco] diciendo que si se echase por tierra toda la obra, él la haría con honestidad y decencia no inferior a aquella en bondad de pintura. De donde, provocados todos los pintores y aquellos que disfrutan con esta profesión, le fue necesario marcharse a España donde, bajo Felipe II, hizo muchas cosas de gran gusto. El Juicio Final de la Sixtina llevaba décadas de polémica, alcanzando su punto álgido con Pío V y Gregorio XIII, época en la que la obra corrió serios peligros de destrucción. Dominico intervino en la polémica e hizo una propuesta radical, que le granjeó multitud de enemistades (De Maio, 1981).

Desde 1573 en Roma se tenía cumplida noticia de las necesidades de obras de arte que tenía Felipe II para el ornato del Monasterio de San Lorenzo el Real del Escorial. En 1573 se le informa sobre el tabernáculo trazado por Miguel Angel, y que tenía a medio hacer Giacomo del Duca y las noticias sobre pinturas y pintores era constante. A medida que avanzaba la década se convierte en algo recurrente, y en la correspondencia oficial, el nombre del Escorial aparece de continuo, ya para arquitectura, ya para ornato. Desde su llegada a Roma, el Greco se estaba moviendo dentro de los ambientes filoespañoles, cuya cabeza incontestable era el Cardenal Alejandro Farnese. A pesar de caer en desgracia con ese príncipe de la Iglesia, el artista mantuvo los contactos con el círculo a través de Fulvio Orsini y de Giulio Clovio. Pero seguimos careciendo de datos precisos que aclaren estas relaciones. Sea como fuere, en 1577 Dominico Greco partió de Roma hacia España. Había vivido diez años en Italia; había conseguido un arte excelente y depurado dentro de la corriente italiana, tenía su propia maniera y había adquirido una amplia cultura. Pero no había logrado cubrir sus ambiciones y expectativas.
El Greco llegó a España con treinta y seis años (Hadjinicolaou, 2005). Se dirigió a la Corte, que estaba en Madrid, donde es posible que tuviese algún contacto, aspirando a conseguir alguno de los encargos que hacía Felipe II, de los que tanto se hablaba en Roma. Acaso fuese con una carta de Giulio Clovio al Rey, similar a la que le diera en 1570 para el Cardenal Farnese. Pero las cosas se presentaban difíciles, pues el 21 de agosto de 1576 Juan Fernández de Navarrete, el Mudo, se había encargado de treinta y dos cuadros para otros tantos retablos, que decorarían la Basílica, y el retablo mayor todavía estaba sin terminar de trazar (Bustamante García, 1993).

A la vez el candiota tenía también contactos en Toledo, en el entorno de la Catedral, otro cliente de gran envergadura. Luis de Castilla, al que había conocido en Roma y con el que entabló una buena y duradera amistad, era hijo del Deán Diego de Castilla. Y aquel contacto funcionó. La pintura toledana de esas fechas no era precisamente brillante así que, ante cualquier muestra de su arte que presentara Theotocópuli, ningún artista del lugar podría equiparársele. El 2 de julio de 1577 el Cabildo le encarga la ejecución de un gran cuadro de altar para la Sacristía catedralicia, cuyo tema era el Expolio. Un gran lienzo de $285 \times 173 \mathrm{~cm}$. La obra más grande que hasta ese momento hubiese podido pintar. En junio de 1579 la obra ya estaba pintada y el Obrero catedralicio García de Loaísa y el pintor acordaban que se tasara. La obra había tardado dos años en pintarse y el resultado era y es espectacular. Cuando la obra fue vista y tasada se produjo un terremoto. El cuadro era algo nunca visto en Toledo. Hoy se diría que la pintura del Expolio era un episodio de la vanguardia más rabiosa de la pintura italiana en Toledo. La calidad del lienzo les lleva a decir a los tasadores, que es tan grande, que no puede ser tasado; pero que dada la miseria de los tiempos, lo valoran en la enorme suma para España de novecientos ducados. Respecto a la calidad artística del Expolio, quien mejor la define es el nada amigo de El Greco Juan Bautista Monegro, cuando escribe hacia 1611, con respecto a la decoración de la Sacristía catedralicia, que las figuras de pintura y escultura que tienen que ir sean esbeltas, para que en su sitio hagan buen efecto; pintura y escultura se pretende se haga lo mejor que fuere posible, por estar en dicha sacristía en el altar y retablo de ella una pintura del natural historia del Despojo de Cristo de mano de Dominico Greco lo mejor que hizo, y debajo de ella una historia de medio relieve toda dorada de mano del dicho autor (Marías, 1982, 2013 y 2014). 
El Cabildo catedralicio no estaba dispuesto, de ninguna manera, a pagar dicha cantidad. No solo reclamó una nueva tasación, pues consideraba el precio desorbitado para España, sino que empezó a poner adversativas de carácter sagrado a la pintura. La mezcla de disputa económica por el precio y consideraciones sagradas respecto al modo de representar el Expolio o Despojo de Cristo no es muy acertado. Era una carga en toda regla por parte del Cabildo, pero de asuntos distintos. Económicamente el cuadro podía valer eso y más, siempre que se aceptase el concepto de obra de arte según los parámetros italianos. Y en España eso no se deba ni por asomo. Una obra de arte era una simple actividad artesanal. A regañadientes se podía aceptar una calidad extraordinaria, lo que justificaba una cierta demasía, pero nunca los novecientos ducados en que se había tasado. Después de mucho lidiar, la obra quedó tasada en un tercio de su primer valor. El comitente se había impuesto al artista. Y si esa era la Catedral Primada, ¿que se podía esperar de clientes de menor categoría? España no era Italia (Zarco del Valle, 1870 y 1916; Pérez Sedano, 1914).

Respecto a la crítica de carácter sagrado hecha al lienzo, con sus impertinencias y faltas de decoro, así como el más temible ataque a la situación de las santas mujeres tan próximas a Cristo en el Gólgota podía llevar a una situación muy peligrosa. Los ataques de impropiedad solían darse con cierta frecuencia, y a El Greco le dio de lleno, como pocos años después le pasará a él mismo y a Federico Zuccari pintando en El Escorial para Felipe II. El momento que refleja el cuadro de la Sacristía catedralicia no está descrito en los Evangelios. Durante los años en que se encargó el cuadro y se pintó, el texto más empleado para tratar estos episodios de la Pasión eran la Primera y Segunda Parte del Monte Calvario de fray Antonio de Guevara, con trece ediciones entre 1545 y 1582, y cuya descripción de como llegó Cristo al Gólgota y allí le despojaron de sus ropas a redopelo es devastadora. Muy en línea del modo de hacer de El Greco, el acontecimiento está representado con fidelidad: el Calvario, el sayón perforando y disponiendo la cruz, las santas mujeres, María, María Cleofás y María Magdalena contemplando horrorizadas como se dispone el madero; Cristo es el eje y centro de toda la composición, está cubierto con su túnica carmesí y espera mansamente mirando al cielo que le arrebaten las vestiduras para, a continuación, ser crucificado; sayones y soldados forman un tropel alrededor de Jesús y, entremezclados, crean una descomunal algarabía que cae sobre Cristo y van a empezar a despojarle de sus ropas, como lo refleja el acto del malencarado sayón de verde. Los soldados llevan armamento moderno y portan picas, alabardas y partesanas. Esta disyunción respecto a un episodio de la época de Tiberio no agradaba a los capitulares toledanos, pero tampoco era tan grave; en cuanto a la turba que caía sobre Cristo, no debió ser difícil justificarla al pintor: era la maldad humana en acción, una jauría salvaje sobre una víctima indefensa, el episodio más repugnante de todo ese acontecimiento, desde la claudicación de Poncio Pilato a la muerte de Cristo. La reciente limpieza del cuadro muestra algunos cambios en las santas mujeres, que Marias juzga como cesiones a sus comitentes, y que en absoluto alteran el cuadro (Alonso Alonso, 2014, Marías, 2014). Theotocópuli había tratado el Expolio de una forma completamente novedosa y con una calidad pictórica sin precedentes. Curiosamente, el Cabildo puso objeciones, pero jamás rechazó el cuadro. Se reconocía su extraordinario valor.

El 8 de agosto de 1577 el Deán de la Catedral de Toledo don Diego de Castilla encarga a El Greco la hechura de una obra todavía mayor: los tres retablos que adornarán la capilla mayor de la iglesia del Convento de Santo Domingo el Antiguo. Significativamente, el pintor le hará un precio especial: por todo ello cobrará mil ducados (San Román, 1982; Álvarez Lopera, 2007; Marías, 2013 y 2014). La empresa era la más grande que el candiota hubiese podido tener hasta entonces. El retablo mayor lo forman seis lienzos, dos de gran tamaño: la Asunción de la Virgen en el cuerpo (Chicago, Art Institute) y la Trinidad en el remate (Madrid, Museo del Prado). Flanqueando el episodio mariano los Santos Juanes, in situ, el Bautista en el lado del Evangelio, y el Evangelista con iconografía novedosa en la Epístola; encima San Bernardo (San Petersburgo, Hermitage) y San Benito (Madrid, Museo del Prado). Los correspondientes retablos laterales lo forman sendos lienzos de gran formato: la Adoración de los pastores con San Jerónimo (Madrid, Fundación Botín), y la Resurrección de Cristo con San Ildefonso, en su lugar original. A punto de acabar la empresa, se encarga al candiota en 1579 la Santa Faz que remata el cuerpo principal del retablo mayor (Palma de Mallorca, Colección March Servera). Don Diego de Castilla quedó plenamente satisfecho y El Greco colocaba el más espectacular conjunto italiano en el corazón Toledo, superando incluso al mismísimo Navarrete el Mudo y a la gran empresa pictórica del Escorial. Con estas dos empresas el genial Dominico situaba a Toledo a la cabeza de la innovación pictórica en España. Y Felipe II lo tuvo muy presente. 
El 7 de enero de 1579 el retablo mayor del Monasterio del Escorial, junto con los cenotafios reales, cuyas trazas eran de Juan de Herrera, se asignan a Jacopo da Trezzo, Pompeo Leoni y Giovanni Battista Comane, mientras que la pintura del retablo sería hecha por Navarrete el Mudo. El 10 de ese mes se otorgaba la escritura de concierto de la arquitectura y la escultura, mientras que el pintor seguía presentando algunos reparos en el contrato (Mulcahy, 1992; Bustamante García, 1993). Navarrete marchó a Toledo muy quebrantado de salud para seguir allí la obra escurialense, pero fallecerá allí, en la casa de Nicolás de Vergara el 28 de marzo de 1579. De golpe toda la parte pictórica del ornamento de la Basílica se vino abajo.

Felipe II intentó recomponer la situación contratando a diversos pintores para los diferentes retablos, dejando la pintura del mayor detenida. Felipe II pasó la fiesta del Corpus Christi en Toledo, entre el 18 y el 20 de junio. Allí tuvo ocasión sobrada para oír hablar de El Greco. El éxito y la polémica de septiembre de 1579 con la presentación del Expolio y el conjunto de Santo Domingo el Antiguo debieron llegar también a los oídos del Rey Prudente, el cual necesitaba a artistas de envergadura para seguir con su empresa. Para colmo, la plaza de Navarrete estaba vacante. Theotocópuli vio la oportunidad y consiguió esta vez un encargo regio, en el que ya estaba trabajando en 1580: la hechura de un gran cuadro de altar para la Basílica con el tema del martirio de San Mauricio y la legión tebana.

El pintor realizó la obra en Toledo, tuvo sus enfrentamientos con la Congregación de la fábrica y no fue al Escorial hasta el 16 de noviembre de 1582, cuando en persona entregó el cuadro, el cual tenía que ser tasado y llevaba recibido a cuenta del mismo quinientos ducados. La obra le había llevado casi tres años de trabajo. Entre el 24 y el 27 de marzo de 1583 Felipe Il estuvo en el Real Monasterio, vio el cuadro, no le gustó y ordenó tasarlo, pagando a El Greco la cantidad de ochocientos ducados por la obra.

Fray José de Sigüenza arremete contra el pintor violentamente, le niega el pan y la sal, considera que el cuadro no es bueno, ni el arte del cretense de calidad por más que digan algunos; para concluir su diatriba en aquello que más le sacaba de quicio: Tras esto, como decía en su manera de hablar nuestro Mudo, los santos se han de pintar de manera que no quiten la gana de rezar en ellos, antes pongan devoción, pues el principal efecto y fin de su pintura ha de ser esta (Sigüenza, 1963).
La historia del San Mauricio escurialense es la reiteración de la del Expolio toledano, pero sin mezcla de discusión económica. A pesar de la enorme suma del San Mauricio, el Rey ordena librarla sin el menor comentario, indicativo de que se le reconocía un valor artístico incuestionable. De todos los cuadros para la Basílica hasta ese momento hechos, ninguno había alcanzado cifra tan enorme. Como se deduce de este silencio, junto con la furibunda inquina de fray José de Sigüenza, lo que no gustaba de El Greco es que su cuadro no inspiraba devoción, no era un cuadro devoto. $Y$ eso era algo crítico, tanto para los capitulares toledanos con el Expolio, como para el Monarca Católico en la Basílica del Escorial.

El candiota había seguido fielmente las pautas dadas por Felipe II, que eran las proporcionadas a Navarrete el Mudo en 1576, y las cumplió al pie de la letra (Bustamante García, 1992 y 2003). En primer lugar, no siguió la corriente germánica de presentar a San Mauricio negro, como lo hicieran Matthias Grünewald en el cuadro de San Erasmo y San Mauricio (ca. 15201524, Munich Alte Pinakothek) o Lucas Cranach el Viejo en su San Mauricio (ca. 1520-1525, Metropolitan Museum of Art de Nueva York); sigue la tradición francesa e italiana de un hombre blanco. Las veces que pinta a San Mauricio y a sus compañeros siempre lo hace con los mismos rostros, vestidos y colores, no hay animales, salvo la serpiente que porta la cartela con la firma; las citas históricas son rigurosas, pero no arqueológicas, y hay disyunciones como las armas y los armados, a igual que en el Expolio. Y lo mismo que en el cuadro toledano, donde lo que se representa es el momento con toda su atrocidad en que la turba va a arrancar a Cristo sus vestiduras a redopelo, es decir, a contrapelo, como diría fray Antonio de Guevara, en el cuadro escurialense está en primer plano la decisión que toman los capitanes de no acatar la orden de adorar a las divinidades. El castigo de la legión y el martirio queda detrás. El Greco no valoraba lo sanguinolento, ni lo horroroso, aunque intenta acallar a los que tanto les place esas cosas con el cadáver decapitado que está en el suelo. Lo que buscaban Felipe II y los jerónimos era lo que El Greco no estaba dispuesto a aceptar. Su representación no se ceñía al decoro que se le pedía. Y por ello Sigüenza le niega todo con su proverbial acrimonia y prosa maravillosa.

Y a igual que en la Catedral de Toledo Dominico Theotocópuli pinto sendas obras maestras, con las que se quedaron sus comitentes, pero no volvieron a encargar más al artista obra alguna. La independencia de El Greco no era tolerable, pero la calidad de las 
pinturas eran plenamente aceptadas. El fracaso en cuanto a satisfacer las exigencias que imponían el Cabildo toledano y el Rey mostraban a las claras que el pintor no podía ser una persona en nómina de tales comitentes, como tantos y tantos artífices buscaban. La independencia personal solo se consigue con la económica. Para que el pintor siguiera con su modo de vida y su modo de ser, no podía ser un asalariado con nómina fija; tenía que vivir de lo que él se buscase. Había que buscar clientes y, llegado el momento oportuno, montar un taller.

En relación con el mundo de la Corte, hay que situar el enigmático cuadro conocido como la Gloria de Felipe II, que estaba en la Sacristía del Panteón Real, llevada allí por Felipe IV. El tema es un auténtico enigma, pero su carácter apocalíptico es bien patente. El Greco recurre a elementos ya planteados en el Tríptico de Módena para representar las postrimerías y los espantos apocalípticos de ese momento final. El cuadro parece enmarcarse en la época en que pintó el San Mauricio, pero nada sabemos, ni de su comitente, ni de su historia hasta que aparece en la Sacristía del Panteón del Escorial.

En relación con el Deán don Diego de Castilla está el soberbio cuadro de San Sebastián de la Catedral de Palencia, posible regalo de este palentino a su antigua Catedral (Marías, 2013). El Greco procuraba por todos los medios conseguir encargos, y en esta línea estarían la Crucifixión del Museo del Louvre (ca. 15771580) y la Visión de San Lorenzo de Monforte de Lemos (ca. 1578-1580).

Los cuadros de devoción se completan con los retratos, El caballero de la mano en el pecho (ca. 1579, Madrid, Museo del Padro) y los retratos de Antonio de Covarrubias (París, Museo del Louvre) y de su hermano Diego (Toledo, Casa y Museo de El Greco), ambos de hacia 1586, son los grandes pasos del venecianismo en el retrato español, y el gran contrapeso de la todopoderosa tradición flamenca representada por el retrato de corte impuesto por Antonio Moro. Una vez más El Greco marcaba pautas desde Toledo.

Colofón de esta serie de continuos trabajos y resultados artísticos excelentes, fue el encargo que recibió de su parroquia de Santo Tomé de Toledo, el 18 de marzo de 1586, de pintar el piadoso acontecimiento del entierro del Señor de Orgaz Gonzalo Ruiz de Toledo, fallecido, según su epitafio, en 1323. El tema era una piadosa tradición toledana del siglo XIV, vinculada, tanto a la parroquia, como al convento de los agustinos. El párroco Andrés Núñez de Madrid la reactivó, no solo recuperando derechos que la parroquia tenía con respecto a los vecinos de Orgaz, sino haciendo la capilla de nuevo donde se hallaban los restos del piadoso caballero, los cuales no fueron tocados durante el proceso constructivo. Como remate de la empresa, el párroco pretendió representar el milagroso entierro del Señor de Orgaz, pero se encontró con el grave problema en aquellas fechas, de que aquello era una tradición tolerada, pero no sancionada por la Iglesia. El rigorismo en cuanto a las imágenes y las historias sagradas estaba en pleno apogeo en todo el orbe católico. No solo se estaban depurando tradiciones antiguas y repudiando textos y hasta santos y episodios, sino también se estableció un estricto control de las imágenes por parte de los obispos a través de las visitas y la centralización de obras por los vicarios diocesanos. El escándalo del Expolio de 1579 en la mismísima Catedral Primada era un paradigma; la falta de decoro del San Mauricio en el estrictísimo San Lorenzo el Real del Escorial era otro aldabonazo; pero en Santo Tomé la cosa iba a mayores, pues lo que se pretendía pintar era un acontecimiento sacro que la Iglesia no había sancionado. El párroco, muy prudentemente, se dirigió al Arzobispo don Gaspar de Quiroga, el cual tras rigurosas pesquisas, dio provisión y licencia para pintarlo el 23 de octubre de 1584.

Theotocópuli pintó la historia en casi dos años. Fue tasada en mil doscientos ducados; no hubo conformidad y una segunda tasación elevó el precio a mil seiscientos; tras serias discusiones, se acabó aceptando por las partes la primera cantidad. Alonso de Villegas dice que la pintura se hizo, y es una de las buenas cosas que hay en España, y costó sin la guarnición y adorno mil y doscientos ducados. Fue el artífice y pintor Dominco Theotocópuli, da nación griego (Villegas, 1614). Es el cuadro más grande que pinto el artista en toda su vida: 480 x $360 \mathrm{~cm}$. El tema era representar el hecho milagroso del entierro del Señor de Orgaz, consistente en que, cuando estaba todo listo para depositar su cuerpo en la sepultura, aparecieron de improviso San Estaban y San Agustín, los cuales cogieron el cuerpo con sus manos y lo depositaron en la tumba ante la admiración de los asistentes. El Greco aborda a la vez el milagro en la tierra y la santificación en el cielo, partiendo el cuadro en dos segmentos. En el inferior está el sepelio con los asistentes al mismo entre los cuales el pintor, fiel a la tradición veneciana, representa el hecho en el siglo XVI e introduce personajes conocidos, empezando por el mismo Cardenal Quiroga como San Agustín, o Antonio de Covarrubias. El mundo celeste, separado por las nubes, muestra el juicio del alma del difunto, y como gracias a la inter- 
cesión de la Virgen y toda la corte celestial, es admitida entre los justos, dejando patente de este modo la salvación del Señor de Orgaz (Álvarez Lopera, 2005 y 2007; Marías, 2013 y 2014).

Desde entonces Dominico no deja de pintar obras de devoción, como la Sagrada Familia (ca. 15901595, Toledo, Hospital Tavera), La Inmaculada (ca. 1595, Toledo, Museo de Santa Cruz) e historias sagradas como la Apertura del Quinto Sello (ca. 1608, Nueva York, Matropolitan Museum of Art), así como santos, ya en solitario, ya en series, siendo su punto álgido las pinturas de San Francisco (ca. 1600, Ottawa, National Gallery). El retrato es un género en el que no tiene rival durante toda su vida, ya sea de busto, como el caballero anciano del Museo del Prado, medio cuerpo o cuerpo entero, en especial sedentes, como el Cardenal Hernando Niño de Guevara (ca. 1600, Nueva York, Metropolitan Museum of Art) o el sensitivo fray Hortensio Félix Paravicino (ca. 1608, Boston Museum of Fine Arts). Esta intensa actividad se remata con obras mitológicas, como el Laocoonte (ca. 1610, Washington, National Gallery of Art) así como sus incursiones en el género de las vistas, con al extraordinaria Vista de Toledo (ca. 1600, Nueva York, Metropolitan Museum of Art) y la no menos espectacular Vista y Plano de Toledo (ca. 1610, Toledo, Casa y Museo de El Greco).

Pero la médula de los grandes trabajos toledanos del cretense desde finales del siglo XVI hasta su muerte fueron los grandes conjuntos retablísticos. El primero y más espectacular fue el retablo mayor del Colegio de doña María de Aragón en Madrid (15961600), del que se conservan las pinturas en el Museo del Prado y en el de Bellas Artes de Bucarest (Ruiz Gómez, 2001; Álvarez Lopera, 2007; Marías, 2013) y cuya estructura es tema de discusión. Allí El Greco desarrolla con todo su potencial, tanto la pintura de borrones, como los efectos lumínicos, el dramatismo de las sombras y la estilización del cuerpo humano, características que forman su llamado estilo final. El retablo era todo un episodio en Madrid, por completo diferente a la medida y clásica pintura de los artistas de la Corte. El conjunto de la Capilla de San José de Toledo (1597-1599) siguen la misma línea con un preciosismo extraordinario, tanto en el San José y la Coronación de la Virgen del retablo mayor, como en el San Martín y la Virgen con el Niño y santas de los retablos laterales, hoy ambos en la National Gallery of Art de Washington (Marías, 2014). El virtuosismo cromático y alargamiento de las figuras alcanza su máximo efecto en el conjunto de la iglesia del Hospital de la Caridad de Illescas (1603-1605), donde a todo ello se une los juegos ópticos, los efectos de visión y el dramatismo más extremo con la sombra y la luz, así como una interpretación en esas claves de un interior y un exterior con los grandes cuadros de San Ildefonso escribiendo y la Virgen de la Caridad de los retablos laterales (Marías, 2014). En 1608 Dominico se obligaba a hacer el retablo mayor y dos colaterales para la Capilla del Hospital de San Juan Bautista de Afuera. Nada se sabe de cuales iban a ser sus pinturas. Cuando el pintor muere en 1614 había algunos cuadros empezados (Marías, 2014). El artista moría como había vivido, con los pinceles en la mano. Dejaba bienes y un prestigio. Aquel Dominico Griego que había llegado a España en 1577 con su saber y su valor, había hecho una larga carrera y había triunfado.

\section{BIBLIOGRAFÍA}

Alonso Alonso, R. (2014). Mirando el cuadro de El Expolio de El Greco. El Expolio de Cristo de El Greco. Toledo: Instituto Teológico de San Ildefonso de Toledo.

Álvarez Lopera, J. (1987). De Ceán a Cossío: la fortuna crítica del Greco en el siglo XIX. EI Greco: textos, documentos y bibliografía. Madrid: Fundación Universitaria Española.

Álvarez Lopera, J. (2005). El Greco. Estudio y catálogo (volumen I. Fuentes y bibliografía). Madrid: Fundación de Apoyo a la Historia del Arte Hispánico.

Álvarez Lopera, J. (2007). El Greco. Estudio y catálogo (volumen II. Tomo 1. Catálogo de obras originales: Creta, Italia. Retablos y grandes encargos en España).
Madrid: Fundación de Apoyo a la Historia del Arte Hispánico.

Bialostocki, J. (1966). Puer sufflans ignes. Arte in Europa. Scritti di Storia dell'arte in onore di Odoardo Arslan. Milán: Artipo.

Bustamante García, A. (1992). Gusto y decoro. Felipe II y El Escorial. Academia, 74, pp. 163-198.

Bustamante García, A. (1993). Las estatuas de bronce de El Escorial. Datos para su historia (I). Anuario del Departamento de Historia y Teoría del Arte, V, pp. 41-57.

Bustamante García, A. (2000). El renacimiento español desde el siglo XIX. En Reyero, C. y Martínez Millán, J. (coords.) El siglo de Carlos V y Felipe II. La cons- trucción de los mitos en el siglo XIX (vol. 1), pp. 101-118.

Bustamante García, A. (2003). El Greco y Felipe II. El Martirio de San Mauricio de El Escorial. En AA. VV. El Greco. Barcelona: Galaxia Gutenberg, Círculo de Lectores, pp. 217-230.

Bustamante García, A. (2003a). Creadores forasteros de la historia del arte español. En Cabañas Bravo, M. (coord.). El arte español fuera de España, Madrid: Consejo Superior de Investigaciones Científicas, pp. 459-468.

Bustamante García, A. (2005). Forasteros y nacionales. Aspectos sobre el estudio del arte en España. En Cabañas Bravo, M. (coord.). El arte foráneo en España. 
Presencia e influencia. Madrid: Consejo Superior de Investigaciones Científicas, pp. 579-587.

Carducho, V. (1979). Diálogos de la pintura Su defensa, origen, esencia, definición, modos y diferencias. Madrid: Turner.

Cossío, M. B. (1972). El Greco. Barcelona: R. M.

De Maio, R. (1981). Michelangelo e la Controriforma. Roma-Bari: Laterza.

Gállego, J. (1976). El pintor de artesano a artista. Granada: Universidad de Granada.

Hadjinicolaou, N. (ed.) (1995). El Greco of Crete. Iraklion: Municipality of Iraklion.

Hadjinicolaou, N. (ed.) (1999). El Greco in Italy and Italian Art. Rethymno: University of Crete.

Hadjinicolaou, N. (ed.) (2005). El Greco. The first twenty years in Spain. Rethymno: University of Crete.

Hadjinicolaou, N. (ed.) (2007). El Greco's Studio. Iraklion: Crete University Press.

Mancini, G. (1956). Considerazioni sulla pittura. Roma: Accademia Nazionale dei Lincei.

Mann, R. G. (1994). El Greco y sus patronos. Tres grandes proyectos. Madrid: Akal.

Marías Franco, F. y Bustamante, A. (1981). Las ideas artísticas de El Greco (Co mentarios a un texto inédito). Madrid: Cátedra.

Marías, F. (1982). Arquitectura y ciudad Toledo en la época de El Greco. El Toledo de El Greco. Madrid: Ministerio de Cultura.
Marías, F. (2013). El Greco. Historia de un pintor extravagante. San Sebastián: Nerea.

Marías, F. (ed.) (2014). El Griego de Toledo. Pintor de lo visible y lo invisible. Madrid: El Viso.

Martínez, J. (2006). Discursos practicables del nobilísimo arte de la pintura. Madrid: Cátedra.

Mulcahy, R. (1992). A mayor gloria de Dios y el Rey: La decoración de la Real Basílica del Monasterio de El Escorial. Madrid: Patrimonio Nacional.

Pacheco, F. (1611/1990). El arte de la pintura. Madrid: Cátedra.

Palomino, A. (1947). El museo pictórico y escala óptica. Madrid: Aguilar.

Panagiotakes, N. M. (2009). El Greco. The Cretan Years. Aldershot: Ashgate.

Pérez Sedano, F. (1914). Datos documentales inéditos para la Historia del Arte Español. I. Notas del Archivo de la Catedral de Toledo, redactadas sistemáticamente, en el siglo XVIII, por el canónigo obrero don Francisco Pérez Sedano. Madrid: Centro de Estudios Históricos.

Pérez de Tudela, A. (2000). Una carta inédita de El Greco al Cardenal Alessandro Farnesio. Archivo Español de Arte, 291, pp. 267-268.

Pérez de Tudela, A. (2001). A proposito d una lettera inedita di El Greco al Cardinale Alessandro Farnese. Aurea Parma, LXXXV, II, pp. 175-188. http://dx.doi. org/10.3989/aearte.2000.v73.i291.830

Pita Andrade, J. M. (1984). Dominico Greco y sus obras a lo largo de los siglos XVII y XVIII. Madrid: Real Academia de Bellas Artes de San Fernando.
Riello, J. (2014). La biblioteca del Greco. En Docampo, J. y Riello, J. (eds.) La biblioteca del Greco. Madrid: Museo del Prado, pp. 41-77.

Ruiz Gómez, L. (ed.). (2001). Actas del congreso sobre el retablo del Colegio de doña María de Aragón del Greco. Madrid: Museo del Prado.

Salas, X. de y Marías Franco, F. (1992). El Greco y el arte de su tiempo. Las notas de El Greco a Vasari. Madrid: Real Fundación de Toledo.

San Román, F. de B. (1982). El Greco en Toledo. Vida y obra de Domenico Theotocópuli. Toledo: Zocodover.

Sigüenza, J. de (1963). Fundación del monasterio de El Escorial. Madrid: Aguilar.

Villegas, A. de (1614). Flos Sanctorum: tercera parte. Valladolid: Francisco Fernández de Córdoba.

Zarco del Valle, M. R. (1870). Colección de documentos inéditos para la historia de España (tomo LVI. Documentos inéditos para la historia de la las Bellas Artes en España). Madrid: Viuda de Calero.

Zarco del Valle, M. R. (1916). Datos documentales para la Historia del Arte Español. (II. Documentos de la Catedral de Toledo). Madrid: Centro de Estudios Históricos.

Zeitler, K. y Hellwig, K. (2006). El Greco kommentiert den Wettstreit der Künste. Eine Zeichnung in der Staatlichen Graphischen Sammulng München. München Berlin: Deutscher Kunstverlag. 